7. HISTORIA DEL PENSAMIENTO JURÍDICO 

Revista de Estudios Histórico-Jurídicos

[Sección Historia del Pensamiento Jurídico]

XXXIV (Valparaíso, Chile, 2012)

[pp. $431-456$ ]

\title{
LA RECEPCIÓN DE LAS IDEAS JURÍDICAS DE RAMON LLULL EN LOS SIGLOS XV Y XVI
}

[The Acceptance of the Legal Ideas of Ramon Llull in the $15^{\text {th }}$ and $16^{\text {th }}$ Centuries]

\author{
Rafael Ramis Barcelo* \\ Universitat de les Illes Balears, España
}

\begin{abstract}
RESUMEN
Este artículo explica el desarrollo de las ideas jurídicas de Ramon Llull durante los siglos XV y XVI. Es una línea inexplorada en la historia de las ideas jurídicas y trata de determinar la influencia de Llull en los teólogos-juristas y en el humanismo jurídico. Se estudian cuatro autores: Sibiuda, Heymericus de Campo, Lavinheta y Pierre de Grégoire. Estos teóricos conforman la primera etapa del "lulismo jurídico" que florece en la época Moderna.

Palabras clave

Ramon Llull - Sibiuda - Heymericus de Campo - Lavinheta - Pierre de Grégoire.
\end{abstract}

\begin{abstract}
This article explains the development of the legal ideas of Raimundus Lullus during 15th and 16th Centuries. It is a non-developed line in the history of the legal ideas that seek to find the influence of Llull on Legal theologians and on Legal Humanismus. Four thinkers are studied: Sibiuda, Heymericus de Campo, Lavinheta and Pierre de Grégoire. These theorists are the first step of the Legal "Lullismus" that flourishes in Modern Era.

Keywords

Raimundus Lullus - Sibiuda - Heymericus de Campo - Lavinheta - Petrus Tholosanus.
\end{abstract}

RECiBido el 28 de enero y ACEPTADO el 5 de julio de 2012

* Facultat de Dret, Universitat de les Illes Balears, Cra. de Valldemossa, km. 7.5, 07122, Palma de Mallorca, Islas Baleares, España. Correo electrónico: r.ramis@uib.es 


\section{INTRODUCCIÓN**}

La influencia de Ramon Llull en la historia de las ideas jurídicas es una cuestión que ha quedado muy ladeada tanto en los estudios lulianos como jurídicos. Sin embargo, los juristas, filósofos y teólogos tuvieron interés en la concepción luliana del derecho, que pasó a formar parte de las distintas doctrinas en boga desde el siglo XV hasta el XVIII. A partir del XIX, gracias fundamentalmente a Savigny ${ }^{1}$, Llull fue un autor que interesó a los historiadores y a los filósofos del derecho, ya no como un pensamiento vivo o aplicable, sino como una doctrina relevante en la historia del pensamiento jurídico.

Se propone estudiar en este trabajo la recepción de las ideas jurídicas de Ramon Llull en los siglos XV y XVI. Es una primera aproximación a un tema prácticamente virgen ${ }^{2}$, que pretende mostrar que en el campo de las ideas jurídicas la obra de Llull tuvo un peso relevante y que los escritos del Doctor Iluminado interesaron, en momentos sucesivos, a algunos de los pensadores y escritores más destacados de cada época. El interés de juristas, filósofos y teólogos no sólo se tradujo en mera curiosidad científica, sino que las ideas jurídicas de Llull fluyeron y sirvieron para pensar los problemas de cada momento. Mientras que en buena parte del siglo XV estuvieron presentes en su vertiente más teológica y política, a finales de esta centuria y durante el XVI tuvieron una relevante repercusión en la delimitación epistemológica de la scientia iuris y de la ley natural.

Este escrito es el primer eslabón de un proyecto más ambicioso que intenta exponer las líneas generales la influencia de las ideas jurídicas de Llull en la historia, desde finales de la Edad Media hasta nuestros días. En este primer escrito se reúnen autores del Medioevo tardío y de los comienzos de la Modernidad. Interesa ver de qué manera la obra de Llull estuvo presente en el humanismo jurídico y en los debates intelectuales de los siglos XV y XVI. Por su extensión y por la variedad y alcance de las huellas lulianas en las diferentes obras, se tratará en profundidad cada autor, sino que se pretende elaborar aquí un panorama general de la cuestión, cuyo estudio pormenorizado exigiría, como mínimo, dedicar algunos trabajos independientes a las figuras más señeras.

** Agradezco mucho la beca del Max-Planck Institut für Europäische Rechtsgeschichte de Frankfurt, que me facilitó una provechosa estancia y el acceso a buena parte de la bibliografía citada. El profesor Dragos Calma, actualmente Fellow of Alexander von Humboldt Stiftung en la Universidad de Bonn, me permitió acceder a sus estudios sobre Heymericus de Campo y me hizo algunos interesantes comentarios. El profesor Manuel Rodríguez Puerto, de la Universidad de Cádiz, me facilitó sus trabajos sobre el humanismo jurídico y elaboró una serie de sugerencias que me han sido de gran utilidad. El profesor Antonio Planas, de la Universidad de las Islas Baleares, revisó el texto y me hizo algunas importantes observaciones. A los tres, mi más profundo agradecimiento.

${ }^{1}$ Véase la interpretación de SAVIGNY, F. K. von, Geschichte des Römischen Rechts im Mittelalter (Heidelberg, 1850), V, pp. 642-645.

${ }^{2}$ Las dos únicas excepciones que conozco son Andreu de PALMA, Els sistemes jurídics $i$ les idees jurídiques de Ramon Llull (Palma, Les Illes d'Or, 1936); y Elías DE TEJADA, F., Historia del pensamiento politico catalán (Sevilla, Ediciones Montejurra, 1963), II. 


\section{LAS OBRAS JURÍDICAS DE LLULL}

Como es sabido, la idea fundamental que preside el pensamiento luliano es escribir el mejor libro del mundo (el Arte), de manera que en él se pudiesen explicar racionalmente las verdades del cristianismo y sirviese para convertir a los infieles ${ }^{3}$. Para ello, el Doctor Iluminado idea una combinatoria verdaderamente compleja: intenta en un primer momento vincular los atributos divinos con preguntas y otros elementos, de manera que, tras su combinación, se pudiesen encontrar respuestas para todas las preguntas ${ }^{4}$.

Llull, en su afán de divulgar sus ideas, se vale de diferentes formas literarias. Asimismo, en el marco de las florecientes universidades, intenta aplicar el Arte a los saberes de las diferentes Facultades, entre ellas a las de Leyes y Cánones. Ramon Llull escribe cuatro obras en las que aplica su Arte al derecho ${ }^{5}$ : Liber principiorum iuris $^{6}$, Ars iuris ${ }^{7}$, Ars de iure ${ }^{8}$ y Ars brevis de inventione iuris ${ }^{9}$. Estas obras no agotan las perspectivas lulianas sobre el mundo del derecho, sino que en la vasta obra Llull pueden encontrarse desarrollos e ideas sobre temas jurídicos ${ }^{10}$.

El primero de estos libros, escrito entre 1273 y 1275 , debe entenderse en el marco general de la voluntad luliana de escribir sobre los principios generales de los nacientes saberes universitarios. Esta obra presenta -algo ilusamente- la posibilidad de aprehender dichos saberes de forma sencilla ${ }^{11}$. En realidad, no se trata sino de especulaciones de carácter ontológico que, bajo una aparente presentación jurídica, aportan poco al jurista, al filósofo o al teólogo. Las definiciones son tan complejas que lo único que puede extraerse de ellas es la necesidad de remontarse desde un caso concreto a principios generales. Se trata, por lo tanto, de un ejercicio de abstracción y de ontología jurídica, con escasos resultados. Sin embargo, por su densidad ontológica, ésta sería, a la postre, una obra muy llamativa para filósofos y teólogos que quisiesen adentrase, a partir de sus disciplinas, en el saber jurídico.

El segundo libro es el Ars iuris (1275-1281), una obra sustentada sobre los

${ }^{3}$ Véase Domínguez, F. - Gayà, J., "Life" en Raimundus Lullus. An Introduction to his Life, Works and Thought (Turnhout, Brepols, 2008), pp. 3-124.

${ }^{4}$ Sobre el arte luliano, véase: Bonner, A., The Art and Logic of Ramon Llull: A User's Guide (Leiden - Boston, Brill, 2007).

${ }^{5}$ Sobre las obras jurídicas lulianas, véase: RAmis BARCELó, R., "Estudio Preliminar" en Ramon Llull, Arte de derecho (Madrid, Carlos III, 2011), pp. 22 ss.

${ }^{6}$ ROL [= Raimundi Lulli Opera Latina], XXXI (2007), pp. 323-412.

${ }^{7}$ Ars Iuris en Omnium scientiarum Magistri Beati Raymundi Lulli Doctoris Illuminati et Martyris Tertii Ordinis Seraphici Patris Sancti Francisci. Ars iuris et Arbor imperialis (Palma de Mallorca, Miquel Cerdà - Miquel Amorós, 1745), pp. 1-86.

${ }^{8}$ ROL, XX (1995), pp. 119-177.

${ }^{9}$ ROL, XII (1984), pp. 257-389.

${ }^{10}$ Una descripción general de estas obras puede verse en Monserrat QuintanA, A., La visión luliana del mundo del Derecho (Mallorca, IEB, 1987); y en MuÑOz DE BAENA Y SiMÓN, J. L., Llull, un ensayo de epistemología jurídica (Madrid, Universidad de Alcalá de Henares, 1988, tesis doctoral inédita), pp. 291.

${ }^{11}$ Véase Monserrat Quintana, A., La visión luliana del mundo del Derecho, cit. (n. 10), pp. 70-71. 
principios de la anterior y concebida principalmente para dar solución a problemas de carácter jurisdiccional. Llull cree que el mayor problema de la aplicación del derecho es su complejidad y su falta de sistematicidad, extremo que hace que los pleitos se vuelvan interminables. Con la finalidad de abreviarlos ${ }^{12}$, simplifica el sistema anterior, reduciéndolo a una figura geométrica de ocho principios simbolizados con las letras siguientes: A (Deus), B (Actor), C (Ius), D (Reus), E (Anima B), F (Corpus B), G (Corpus D) y H (Anima D) ${ }^{13}$. Como puede verse, su contenido es claramente antropológico y teológico, entremezclando la justicia de Dios con la humana y el fin del cuerpo y del alma tanto del actor como del reo. Llull cree que con la aplicación de las figuras del Ars iuris se pueden obtener las soluciones jurídicas en cada caso. Sin embargo, no es una solución casuística, tal y como sucede en el derecho civil o en el derecho canónico.

El Arte de Llull pasa entonces a simplificarse y cobra entonces mayor importancia la propia estructura combinatoria que la idea ejemplarista de las dignidades divinas. En este sentido, Llull articula en 1304 su obra más ambiciosa en cuanto a la aplicación del Arte a la resolución de problemas jurídicos: el Ars de iure, también llamado Ars iuris naturalis. También esta obra pretende obtener la reducción de todos los derechos particulares (fundamentalmente el civil y el canónico) a principios universales del saber jurídico, pero en esta ocasión se enfatiza especialmente la relación que tienen todos ellos con la ley natural.

Llull divide el libro en dos partes: en la primera de ellas se ocupa de la construcción del árbol del saber jurídico (arbor iuris), y de los principios y de las reglas de éste, mientras que, en la segunda, se tratan cuestiones jurídicas y se muestra cómo a partir del árbol y de los principios y las reglas se puede dar la solución concreta a cada una de ellas. El libro pone nuevamente el acento en la importancia del Arte para resolver casos jurídicos complejos y considera que el derecho es una ciencia prolija. Al igual que dos obras jurídicas precedentes, dicho escrito está principalmente concebido para la aplicación práctica a los casos jurídicos pero, con mayor intensidad que el Liber principiorum iuris y el Ars iuris, dedica prácticamente la segunda parte a mostrar cómo el Arte sirve para dar respuesta a casos difíciles.

Por último, el Ars brevis [quae est] de inventione iuris ${ }^{14}$, escrito en Montpellier en enero de 1308, representa un modelo más complejo de aplicación del Arte al derecho, pues Llull intenta vincular todo su pensamiento filosófico y teológico con el derecho. Mientras que el Arte de Derecho es una obra concebida para demostrar la racionalidad de la ley natural, en el Ars brevis de inventione iuris pone un mayor énfasis en la solución de problemas de derecho civil y canónico a través del comentario de algunos pasajes del Corpus Iuris Civilis y del Corpus Iuris Canonici. Wohlhaupter considera que el Ars brevis de inventione iuris es la obra jurídica más interesante de Llull ${ }^{15}$.

\section{${ }^{12}$ Ars iuris, p. 1.}

${ }^{13}$ Véase la primera figura, Ars iuris, primer folio, s. f.

${ }^{14}$ Véase Wohlhaupter, E., Die "Ars brevis, quae est de inventione mediorum iuris civilis" des Ramon Lull (segunda parte), en Estudis Franciscans, 47 (1935), pp. 161-250.

${ }^{15}$ Wohlhaupter, E., Die "Ars Brevis", cit. (n. 14), p. 196. Wohlhaupter la considera la 
Se encuentran importantes referencias al derecho ${ }^{16}$, entre otras, en cuatro obras de carácter divulgativo, a saber: Llibre de Contemplacióo ${ }^{17}$ (1273-4?), Llibre del Gentil e dels tres savis ${ }^{18}(1273-1275)$ en Blaquerna $^{19}$ (1282-1287) y Llibre de Meravelles $^{20}$ (1287-1289).

En la primera obra, que es una suma de los proyectos y de las ideas del joven Llull, se tratan aislada y esporádicamente algunas cuestiones que actualmente caerían actualmente en las áreas de derecho civil y político, así como también de derecho procesal y derecho mercantil ${ }^{21}$. La segunda es una obra apologética en la que discuten tres sabios, pertenecientes a cada una de las tres religiones del Libro. En ellas se explica la importancia de la justicia como virtud y su relación con las demás virtudes, así como la relevancia de la jurisprudencia (iuris-prudentia) como saber.

El derecho también aparece en el Blaquerna ${ }^{22}$ y en el Llibre de Meravelles, dos novelas que proponen un recorrido por el saber enciclopédico y por la sociedad estamental del siglo XIII. En ellas aparecen frecuentemente referencias al papel del derecho y de la justicia (fundamentalmente tratando la idea del rey como fuente de la justicia divina).

Entre ellos pueden destacarse los escritos siguiendo el esquema del árbol de (raíces, tronco, ramas, ramos, flores, hojas y frutos) del Arbre de ciència o Arbor scientiae $^{23}$ (1296), verdadero compendio del saber filosófico-teológico y social de Llull. Las partes séptima (Arbre imperial) y octava (Arbre apostolical) tratan, respectivamente, del derecho político y del derecho canónico. Su idea principal es dar una explicación completa de cuál debería ser el modelo de la vida y de la organización política de los príncipes y de la Iglesia. Su disposición, siguiendo la metáfora del árbol, permite una estratificación social muy plástica, de acuerdo con lo que Llull piensa de cada uno de los miembros de una sociedad bien organizada.

El Arbre exemplifical es la parte decimoquinta del Arbre de ciència en el que se congregan una serie de proverbios que sirven para ilustrar a los lectores y facilitarles el acceso a su pensamiento. En la misma línea sapiencial del Arbre exemplifical puede situarse el Liber proverbiorum ${ }^{24}$ (1296), que contiene numerosos prover-

mejor obra jurídica de Llull, pero cree que los resultados que pueden conseguirse a través de ella son prácticamente nulos, véase pp. 196-215.

${ }^{16}$ Para las obras no jurídicas que contienen referencias al derecho, véase RAMIS BARCELó, R., "Estudio Preliminar", cit. (n. 5), pp. 37-40.

${ }^{17}$ ORL [= Obres de Ramon Llull], II-VIII (1906-1914), 381 pp.

${ }^{18}$ NEORL [ = Nova Edició de les Obres de Ramon Llull], II (1993), pp. 1-210.

${ }^{19}$ NEORL, VIII (2009), 709 pp. Para el derecho es fundamental el libro IV, donde explica la importancia de la ciencia del derecho para abreviar los pleitos.

${ }^{20} \mathrm{OE}$ [= Obres Essencials] (Barcelona, Selecta, 1957 y 1960), pp. 319-511. Los principios jurídico-políticos pueden verse en el libro VII, conocido de forma autónoma como Llibre de les Bèsties.

${ }^{21}$ Una explicación más detallada del contenido jurídico de estas obra puede verse en ANDREU DE PALMa, Els sistemes jurídics, cit. (n. 2), pp. 11-21.

${ }^{22}$ Cabe destacar algunas ideas de derecho político y canónico repartidas en toda la obra.

${ }^{23} \mathrm{OE}, \mathrm{I}$ (1957 y 1960) fundamentalmente partes V, VI y XVI, pp. 555-1046.

${ }^{24}$ MOG [= Raimundi Lulli Opera Omnia], VI (1737), pp. 283-413. 
bios, entre los que se sitúan algunos de carácter jurídico y moral ${ }^{25}$. De carácter propedéutico (y también divulgativo) destaca Aplicació de l'Art general (1301) ${ }^{26}$, que es una exposición versificada de doscientos versos octosílabos pensados para popularizar la aplicación del Arte a las ciencias particulares, entre las que también se encuentra el derecho.

Llull escribe para su hijo la Doctrina pueril ${ }^{7}$ (1278) en la que se hace eco del aprendizaje de las distintas disciplinas, entre ellas, el derecho ${ }^{28}$. Una visión propedéutica similar se encuentra en el Llibre de cavalleria ${ }^{29}$ (1275-1281) y el Liber clericorum $^{30}$ (1308), concebidos, respectivamente, para consignar los derechos y los deberes de los caballeros y de los clérigos. En un sentido ético destaca el ya citado Llibre d'intenció (1276-1283), cuyo capítulo V trata alguna de las cuestiones jurídicas que interesaban a Llull (acerca del matrimonio, del prelado, del príncipe, de los caballeros, del pueblo, etc.)

Finalmente, en el marco de lo que actualmente podríamos llamar derecho internacional, cabe destacar el Liber de Fine $(1305)^{31}$ y el Liber de acquisitione Terrae Sanctae (1309) ${ }^{32}$. De ellos destacan las de la necesidad de conquistar Tierra Santa o la necesidad de alianzas entre las naciones cristianas para defenderse de los musulmanes, así como también de la unificación de las órdenes militares.

Se ha podido ver como las referencias al derecho, lato sensu, pueden encontrarse en obras muy distintas entre sí por la finalidad a la que están destinadas. Un examen conjunto de todas ellas permite analizar lo que Llull entiende por la esencia del derecho, así como también facilita una comprensión de las divisiones que el propio autor realiza de la materia estudiada.

\section{El tránsito de la EdAd Media al Renacimiento}

En el siglo XIV y parte del XV el ascendiente de la obra de Llull se encuentra en el terreno político-jurídico, a través de obras más divulgativas (Llibre de cavalleria, Blanquerna...) Se ha repetido la idea de que El Libro de los Estados ${ }^{33}$ de Don Juan Manuel recibe una gran influencia del Blanquerna de Llull y, sin duda, las semejanzas con él son notorias ${ }^{34}$.

${ }^{25}$ Destacan cuestiones de derecho canónico y de derecho político. Véanse los capítulos 2, $3,4,11,12$.

${ }^{26}$ ORL, XX (1938), pp. 207-251.

${ }^{27}$ NEORL, VII (2005), 305 pp.

${ }^{28}$ Véanse los capítulos 68, 76, 80 y 81.

${ }^{29}$ ORL, I (1906), pp. 201-247. Véase la edición de A. Soler en "Els Nostres Clàssics" (Barcelona, Barcino, 1988), 245 pp.

${ }^{30}$ ROL, XXII (1998), pp. 305-354.

${ }^{31}$ ROL, IX (1981), pp. 233-291.

${ }^{32} \mathrm{Su}$ edición puede verse en Kamar, E., Projet de Raymond Lull "De acquisitione Terrae Sanctae". Introduction et édition critique du texte, Studia Orientalia Cristiana, 6 (1961), pp. 103-131.

${ }^{33}$ Puede verse Libro de los estados, en Don Juan Manuel, Obras Completas (ed. de J. M. Blecua, Madrid, Gredos, 1981), pp. 195-502.

${ }^{34}$ Véanse las indicaciones de Andreu de PALma, Els sistemes jurídics, cit. (n. 2), pp. 167169. 
Duarte I de Avis, el rey-filósofo, representante más ilustre del lulismo portugués medieval ${ }^{35}$, estuvo también imbuido de espíritu luliano. La obra más característica de este autor es Leal Conselheiro ${ }^{36}$, si bien este monarca muestra mucha afinidad con la estructura política, jurídica y social de Llull, tanto en toda su producción escrita como en sus reformas legislativas ${ }^{37}$. En dicha obra hay numerosísimas referencias al derecho y muchas de ellas están inspiradas en el ideal de la justicia y del derecho de la Doctrina Pueril. Sin embargo, las referencias directas a Llull abarcan obras filosóficas, teológicas y morales, pero no jurídicas.

Entre los juristas interesados por las obras de Llull hay que resaltar algunas personalidades destacadas de Mallorca, que estudian en Italia y desempeñan cargos relevantes ${ }^{38}$. En una primera etapa (siglos XV y XVI) brillan algunos juristas de la Corona de Aragón (en los actuales territorios hispánicos e itálicos) ${ }^{39}$. Sus perfiles biográficos son muy homogéneos: se trata de personalidades que detentan cargos político-jurídicos notorios y de eclesiásticos que ocupan importantes dignidades. Todos ellos tienen en común su dedicación a la docencia y su interés en el arte luliano. Ninguno de ellos vincula el conocimiento del arte con la docencia del derecho, pues sus explicaciones son o bien jurídicas (el Corpus Iuris Civilis o el Corpus Iuris Canonici) o bien metafísicas (estudio de los principios del Arte de Llull).

Entre ellos sobresalen algunos relevantes maestros, tales como Joan Valero ${ }^{40}$, representante del lulismo mallorquín del XV, que deviene el puente entre el lulismo insular y el italiano; Arnau Albertí ${ }^{41}$, que se doctora en cánones en Pavía ${ }^{42}$, es profesor del Estudio General de Lleida y escribe numerosos tratados jurídicos así como sobre el Arte de Llull, o Joan Cabaspre ${ }^{43}$, que ocupa la cátedra luliana del Estudio General de Mallorca.

Mariano Accardi (o Accardo) ${ }^{44}$, también jurista, es un representante italiano de un lulismo de orientación mallorquina, que contribuye a la solidificación del interés en Italia por la obra del Doctor Iluminado. Todos estos autores no llegan

\footnotetext{
${ }^{35}$ Sobre el lulismo en Portugal: PONTES, J. M. DA CRUZ, Raimundo Lulo e o lulismo medieval portugués, en Biblos, 62 (1986), pp. 51-76.

${ }^{36}$ Leal Conselheiro (edición crítica de M. H. Lopes de Castro, prefacio de A. Botelho, Lisboa, IN-CM, 1999); véase el capítulo LXXXI.

${ }^{37}$ Para ver la influencia de Llull en el marco del reformismo franciscano, véase: Dionísıo, J., Literatura Franciscana no Leal Conselheiro de D. Duarte, en Lusitânia Sacra, XIII-XIV (20012002), pp. pp. 491-516.

${ }^{38}$ Véase Planas Rosselló, A. - Ramis Barceló, R., La Facultad de Leyes y Cánones de la Universidad Luliana y Literaria de Mallorca (Madrid, Dykinson - Carlos III, 2011), pp. 9-40.

${ }^{39}$ Sobre este tema sigue siendo imprescindible El lul.lisme a Itàlia. Esbós de sintesi, pp. 221335 y El lul.lisme del Renaixement, pp. 337-391, en Batllori, M., Ramon Llull i el lul.lisme. Obra Completa (edición de Eulàlia Duran, València, Tres i Quatre, 1993), II.

${ }^{40}$ Véase Trias Mercant, S., Diccionari d'Escriptors lul.listes (Palma, UIB-UB, 2009), pp. 443-444.

${ }^{41}$ Ibíd., pp. 23-24.

${ }^{42}$ Planas Rosselló, A. - Ramis Barceló, R., La Facultad de Leyes y Cánones de la Universidad Luliana y Literaria de Mallorca, cit. (n. 38), p. 24.

${ }^{43}$ Trias Mercant, S., Diccionari d'Escriptors lul.listes, cit. (n. 40), p. 93.

${ }^{44}$ Véase Batllori, M., El lul.lisme a Itàlia. Esbós de sintesi, cit. (n. 39), pp. 291-301.
} 
a conectar el estudio del Arte con las cuestiones jurídicas que aparecen en las obras jurídicas de Llull antes mencionadas. La explicación más plausible de este desencuentro es, como se ha apuntado antes, que la difusión de estas cuatro obras específicamente jurídicas no fue muy amplia. Debe citarse asimismo el interés del veneciano Valerio de Valeriis, que entiende el Arte como ciencia ideal ${ }^{45}$. Su obra, muy esquemática, presenta un resumen del Arte y de los árboles de Llull, en el que -de acuerdo con el Arbre de Ciència- se encuentran elementos de derecho y de política ${ }^{46}$.

La obra jurídica luliana que tuvo una mayor difusión fue Ars iuris, de la cual circularon en toda Europa desde el siglo XIV numerosas versiones manuscritas y que fue impresa en Roma en $1516^{47}$. Queda por estudiar, más allá de las consideraciones del P. Batllori ${ }^{48}$ sobre el tema, cuál fue el motivo de dicha edición y quiénes eran los receptores de la misma.

\section{Cuatro PENSAdores influidos POR Llull}

Desde principios del siglo XV hasta finales del XVI hay cuatro grandes autores que tratan -de manera muy distinta- las ideas jurídicas de Llull: Ramon Sibiuda (o Sabunde), Emmerich Van den Velde (más conocido como Heymericus de Campo), Bernard Lavinheta y Pierre de Grégoire (conocido también como Petrus Tholosanus). Los tres primeros son filósofos y teólogos, y sólo el último es un destacado jurista. Lavinheta es un expositor de las ideas de Llull, pero los otros tres utilizan las ideas jurídicas lulianas para articular su propio pensamiento.

Mientras que en Lavinheta se encuentra una voluntad de máxima fidelidad al pensamiento de Llull, en Sibiuda, Heymericus y Pierre de Grégoire, las ideas jurídicas de Llull se acomodan a los problemas filosófico-teológicos de cada autor. A través de estos pensadores puede constatarse que la doctrina luliana se adapta a las inquietudes intelectuales de cada época. En concreto, en un primer momento se trata la doctrina del conocimiento racional de la ley natural y después la posibilidad de construir un "sistema jurídico". Ambos temas preludian el racionalismo jurídico.

\section{Ramon Sibiuda (i?-1436).}

No puede considerarse que Ramon Sibiuda, profesor en la Universidad de Toulouse, sea un exégeta o un compilador de las ideas lulianas. Su propósito y su resultado son demasiado diferentes para entenderlo como un eslabón más en

\footnotetext{
${ }^{45}$ Aureum sane opus in quo ea omnia breviter explicantur, qua scientiarum omnium parens Raymundus Lullus, tam in scientiarum arbore quam arte generali tradit (Augustæ, Micahaël Manger, 1589).

${ }^{46}$ Ibíd., pp. 85-86 y 164-169.

${ }^{47}$ Ars iuris illuminati doctoris Raymundi Lulii: que breuissima est \& artificio quodam intellectuali clauditur (Rome, Iacobum Mazochium, 1516).

${ }^{48}$ Batllori, M., Le lullisme de la Renaissance et du Baroque: Padoue et Rome, en Actes de XIème. Congrès International de Philosophie, 13 (Amsterdam-Louvain, 1953), pp. 7-12. También en BATllori, M., Ramon Llull i el lul.lisme, cit. (n. 39), pp. 385-391.
} 
la cadena que une el pensamiento de Ramon Llull con las ideas de la Modernidad. La obra de Sibiuda tiene identidad propia ${ }^{49}$ y, a diferencia de los escritos de algunos autores posteriores -como por ejemplo Lavinheta- no pretende ser una exposición del pensamiento de Llull, sino una explicación de sus propias ideas a partir de las del Doctor Iluminado.

En Sibiuda se dan la mano el hombre medieval y el renacentista, puesto que su obra contiene tanto ecos que recuerdan a los siglos anteriores como huellas palpables que anuncian nuevos tiempos ${ }^{50}$. Su formación es amplísima, pues abarca prácticamente todas las ramas del saber del momento: artes, teología, medicina y derecho canónico. Sólo le faltaba, al parecer, el grado en leyes para completar unos estudios de extraordinaria amplitud.

Con tal bagaje no es de extrañar que su obra Liber nature sive creaturarum $^{51}$ rebase ampliamente los umbrales de la teología y que se sitúe en un marco antropológico ( $\mathrm{y}$, hasta cierto punto, antropocéntrico), que preludia el humanismo renacentista. Sin duda, Sibiuda adapta el lulismo a dos exigencias: la claridad y el interés humanístico. La exposición de las ideas propias, mezcladas con las de Llull, resultan un compendio de agustinismo humanista, que resulta apto para su estudio escolar y para su lectura por parte de los escritores de su época.

Jaume de Puig, el mayor experto en la obra de este pensador, indica que "Sibiuda da un vuelco sensacional al lulismo. Para salvar su finalidad apologética, sacrificará toda la artillería artística y combinatoria, y procurará reintegrar la actitud luliana de defensa de la fe a los métodos y a las autoridades de la escuela. Desde este punto de vista, Sibiuda es el mayor normalizador de Llull a principios del siglo $\mathrm{XV}^{52}$ ". En efecto, la obra luliana -en manos de este pensador- queda desprovista de la complejísima combinatoria y adaptada al gusto platonizante del momento.

Para Sibiuda hay dos formas de acceder a Dios: la revelada (Biblia) y la racional. La base del iusnaturalismo de Sibiuda se halla en la idea humanista del libro de la naturaleza como modo de conocimiento racional de Dios, siguiendo el modelo del ascenso del entendimiento en los grados de la creación ${ }^{53}$, tal y como se encuentra en San Agustín, San Buenaventura y Llull. Siguiendo a San Agustín y a Llull, Sibiuda asienta las bases de su pensamiento ontológico y moral en la doctrina de los dos amores en pugna $^{54}$ : el amor hacia Dios y el amor hacia sí mismo. Esta doctrina,

\footnotetext{
${ }^{49}$ Sobre Sibuda, véase: PuIg Oliver, J. de, La filosofia de Ramon Sibiuda (Barcelona, Institut d'Estudis Catalans, 1997).

${ }^{50}$ Véase Batllori, M., El lul.lisme del Renaixement, en Ramon Llull i el lul.lisme, cit. (n. 48), pp. 345-347.

${ }^{51}$ Liber nature sive creaturarum. In quo tractatur specialiter de homine et de natura eius in quantum homo, et de his, que sunt ei necessaria ad cognoscendum seipsum et edeum: et omne debitum, ad quo homo tenetur, et obligatur tam deo quam proximo et in sacra pagina egregio professore (citamos por la edición de F. Stegmüller, Stuttgart, Friedrich Frommann, 1966).

${ }^{52}$ Puig Oliver, J. de, La filosofia de Ramon Sibiuda, cit. (n. 49), p. 83 [la traducción es mía].

${ }^{53}$ GonzÁlez Rodríguez, B., La tercera vía: la antropología política de Raimundo Sibiuda, en Res publica, 18 (2007), p. 325.

${ }^{54}$ Liber nature sive creaturarum, Título 139, p. 185. "Et quoniam isti duo amores inter
} 
tan similar también a la idea luliana de las dos intenciones ${ }^{55}$, pone las mismas bases para el iusnaturalismo, al fundir la ontología y la ética en una unidad.

El objeto del amor, para Sibiuda, puede ser sólo Dios o el hombre ${ }^{56}$. Éste tiene primero deberes hacia Dios, que es fuente de justicia y bondad ${ }^{57}$, pues el hombre que ama a Dios se encuentra en el camino correcto tanto desde el punto de vista ontológico como epistemológico ${ }^{58}$. La ley divina corrobora este itinerario racional y ratifica que el primer deber es amar a Dios sobre todas las cosas. Asimismo la base de este deber es el amor a Dios que -según Sibiuda- constituye la fuente de la ley natural ${ }^{59}$, puesto que este deber es la base de la acción humana y deviene, por lo tanto, un deber natural.

Este binomio derecho-deber natural es la base para mantener el orden de la creación: el hombre tiene que amar a Dios por deber natural y le tiene que otorgar el honor y la gloria ${ }^{60}$. Se trata de un deber que es el correlato de un derecho, pues el hombre, si ama a Dios, sigue su inclinación y realiza lo que le es más provechoso para su propia perfección y dignidad humana ${ }^{61}$. La ley natural, por lo tanto, es la manifestación de esa tendencia que tiene el hombre que ama a Dios, y que exalta su verdadera dimensión en la naturaleza.

En la obra de Sibiuda - pese a tratarse de un libro de teología- se encuentra

se pugnant super possessione primitatis, et cum non possit esse nisi unus primus et oportet scilicet quod sit: ideo neces- se est quod uni soli debeatur de iure possessionis et detur possession primitatis seu praerogativa. Et quia omnia iura naturae et omnes creaturae concluserunt, quae non possunt mentiri, quod amor Dei de iure debet esse primus, et quod Deus debet esse res primo amata, et quod ei solus debetur totus amor primus, et nulli alteri, ac habet ex naturali obligatione, quae non possunt negari. Et sic iam declaratum est, quod amor Dei debet habere de iure et iustitia possessionem primitatis et praerogativam, et quod Deus debet esse res primo amata, et etiam natura amoris hoc requirit, quod ei, scilicet Deo, detur, ut iam probatum est, quia nulla res digna est primo amore nostro, nisi Deus. Et exinde concluditur, quod amor Dei, qui solus est, debet esse primus in nobis de iure et debito obligationis".

${ }^{55}$ Una explicación sintética de esta cuestión puede verse en Cruz Hernández, M., El pensamiento de Ramon Llull (Madrid, Castalia, 1977), pp. 216-219.

${ }^{56}$ Puig Oliver, J. de, La filosofía de Ramon Sibiuda, cit. (n. 49), p. 258.

${ }^{57}$ Liber nature sive creaturarum, tít. 141, pp. 187-188: "Et quia amor Dei debet esse primus solum, et tunc est rectus, bonus, iustus, verus, et secundum Deum, ut iam dictum est; et ideo quia amor Dei est prima radix, oportet quod omnia oriantur ab illo, scilicet omnes amores, et quod omnia, quae fiunt, fiant secundum illum amorem. Et quia est prima radix bona, ideo necesse est, quod sit radix omnium bonorum, et origo et fons. Quia qualis est radix, talia sunt omnia, quae oriuntur de radice. Et quia amor Dei quando est primus in nobis, est primum bonum nostrum ideo omnia bona nostra oriuntur ab eo, et nihil est bonum nostrum, nisi oriatur ab ipso, ideo quia est prima iustitia nostra, et ideo omnis iustitia nostra oritur ab ipso. Et etiam esst primum bonum nostrum, ideo est prima lux nostra, et lumen nostrum, a quo oritur omne lumen nostrum, et etiam est omnis rectitudo nostra, a quo oritur omnis rectitudo nostra".

${ }^{58}$ Puig Oliver, J. de, La filosofia de Ramon Sibiuda, cit. (n. 49), p. 261.

${ }^{59}$ Liber nature sive creaturarum, tít. 223, p. 346. "Dictum est in tota parte praecedenti usque huc de debito hominis, ad quod obligatur de iure naturae: et conclusum est et probatum aliquod occultum ese debitum, quod homo debet Deo: et hoc tam ex datis et acceptis, ubi fundatur obligatio debiti, quam ex parte dignitatis Dei, cui primo debetur amor, timor et honor: et hoc etiam requirebat natura amoris".

${ }^{60}$ Puig Oliver, J. de, La filosofía de Ramon Sibiuda, cit. (n. 49), p. 105.

${ }^{61}$ Ibíd., p. 308. 
un desplazamiento hacia una antropología filosófica que abre las puertas a la ley natural ${ }^{62}$. Ciertamente, existen notables coincidencias entre el iusnaturalismo luliano y el sibiudiano: ambos autores son racionalistas y, hasta cierto punto, ejemplaristas ${ }^{63}$. Pero Sibiuda piensa desde el hombre hacia Dios y no desde Dios hacia el hombre. Su teología es un intento de explicación de Dios y de la creación desde la perspectiva del hombre. Frente a Llull, esta visión resulta más "moderna", pues destaca, ante todo, la importancia del hombre como figura central de la creación ${ }^{64}$.

Pero la mayor diferencia entre Llull y Sibiuda se encuentra en que éste simplifica el Arte, buscando (lo que él consideraba que eran) las verdaderas intenciones intelectuales del Doctor Iluminado. Llull cree que, para hallar los principios de la ley natural, los principios y las reglas filosófico-teológicas deben reducirse al Arte $^{65}$, mientras que Sibiuda prescinde del Arte para buscar una convergencia de Llull con el platonismo y el agustinismo.

El iusnaturalismo de Sibiuda se fundamenta, pues, en la contemplación y como relación entre el amor de Dios y el deber del ser humano. En este sentido, Sibiuda toma algunos elementos medievales y los reformula al socaire de las nuevas ideas de corte platónico que germinarían en el Renacimiento. Con ello, el iusnaturalismo de raíz luliana se ve despojado de la combinatoria del Arte y se entiende en un sentido plenamente ejemplarista. La obra de Sibiuda representa una adaptación del pensamiento luliano a las exigencias intelectuales del momento: la vuelta al platonismo, la relación entre Dios y el hombre a través de un iusnaturalismo emanantista, y la ausencia de la combinatoria del Arte que, en siglos posteriores, volvería a ser el centro de atención de los debates intelectuales sobre la obra del polígrafo mallorquín.

\section{Heymericus de Campo (1395-1460).}

Coetáneo a Sibiuda, aunque de una generación posterior, hay que destacar la cada vez más conocida figura de Heymeric van de Velde o Heymericus de Campo. Se trata de un filósofo y teólogo flamenco muy reputado en su época, que estudia en París y en Colonia. En esta ciudad es catedrático durante algunos años y deviene maestro de Nicolás de Cusa. Después de asistir al Concilio de Basilea, se radica en Lovaina, donde ocupa una cátedra hasta su muerte ${ }^{66}$.

${ }^{62}$ Liber nature sive creaturarum, tít. 223, pp. 346-347: "Omnia quae pertinent ad hominem concluduntur in istis duobus, scilicet in debito et in facto, quia ipsum debitum est ius et ipsa solutio factum: sed ipsum debitum est primum et praecedit, et factum debet sequi post debitum; et ipsum factum est ultimum et complementum debiti [...] Ideo postquam habemus infallibilem cognitionem de debito hominis in quantum homo est, ad complendam totam cognitionem de homine necesse est nos habere cognitionem de ipso facto ipsius hominis et de suo facere: utrum ius et facere concordant in homine".

${ }^{63}$ Una discusión sobre el ejemplarismo luliano y el derecho puede verse en RAMIS BARCELó, R., "Estudio Preliminar", cit. (n. 5), p. 59.

${ }^{64}$ Una desarrollo detallado de estas ideas puede verse en Puig Oliver, J. de, La filosofia de Ramon Sibiuda, cit. (n. 49), pp. 89-95.

${ }^{65}$ Véase Ramis Barceló, R., "Estudio Preliminar”, cit. (n. 5), pp. 59-62.

${ }^{66}$ Sobre el autor, véase: Reinhardt, K. (editor), Heymericus de Campo. Philosophie und 
Heymericus es una figura interesante en la historia del pensamiento, pues -al igual que Sibiuda - su mentalidad está a caballo entre la Edad Media y la Modernidad. Por desgracia, su obra todavía no ha sido estudiada con la exhaustividad que merece, pero en los últimos años ha habido una emergencia de interesantes trabajos gracias a la preparación de la edición crítica de su obra. De momento, cabe apuntar-siempre de forma provisional-algunas ideas que deberán ser revisadas y ampliadas en el futuro ${ }^{67}$.

Heymericus escribe dos obras con un importante contenido teológico-jurídico que hasta el momento, y hasta donde alcanzo, han sido estudiadas sólo en un sentido filosófico-teológico. Ambas fueron redactadas - no por casualidad- en el contexto del Concilio de Basilea. Una de ellas es Disputatio [...] de potestate ecclesiastica in concilio Basiliensis collecta ${ }^{68}$ y la otra es Colliget principiorum iuris naturalis, divini et humani philosophice doctrinalium ${ }^{69}$. Mientras que la primera obra tiene interés en un sentido más político, la segunda entra de lleno en el estudio de la ley natural y representa un paso más hacia el establecimiento del iusnaturalismo racionalista que triunfa en los comienzos de la Modernidad.

Colliget principiorum iuris naturalis [...] es una obra que, según resumen Dragos Calma y Ruedi Imbach ${ }^{70}$, tiene tres cometidos: el primero es reunir una colección de juicios filosóficos y teológicos sobre el derecho divino, el natural y el humano; el segundo es mostrar el camino de salvación para quienes sigan estos principios; la tercera es un thesaurus que permite comprender las verdades divinas, naturales y humanas ${ }^{71}$. Pese a que toda la obra tiene interés luliano, conviene estudiar aquí con mayor detenimiento aquellos apartados que tratan directamente temas jurídicos.

Heymericus de Campo no es un jurista, sino un teólogo de la escolástica tardía. Su interpretación del derecho no depende, por lo tanto, del conocimiento

Theologie im 15. Jahrhundert (Regensburg, Roderer, 2009). Algunas obras del autor están traducidas en Imbach, R. - Ladner, P., Heymericus de Campo. Opera selecta (Freiburg, Universitäts Verlag, 2001). En español, Colomer, E., De la Edad Media al Renacimiento (Barcelona, Herder, 1975), pp. 78-118.

${ }^{67}$ En un futuro quisiera estudiar más detenidamente las implicaciones jurídicas de la obra de este autor, a la que hasta el momento he tenido un acceso limitado.

68 "Codex Cusanus" 106, ff. 89r-188r.

69 "Codex Cusanus" 106, ff. 195r-274v.

${ }^{70}$ Calma, D. - Imbach, R., A Fifteenth-Century Metaphysical Treatise: Preliminary Remarks on the "Colliget principiorum" of Heymericus de Campo, en Przeglad Tomistyczny, 14 (2008), pp. 225-276, véanse en concreto las pp. 241-242.

${ }^{71}$ Colliget principiorum iuris naturalis, "Codex Cusanus" 106, f. 273v. "Ut ergo huic operi finis principaliter intentus imponatur [...] sciens, quod intentioni proposite de commemorando fundamentalia philosophie principia in obsequium theologie, consona iuris divini, naturalis et bumani colligentis iudicia aliquatenus satisfeci studiosisque illius veritatis tripartite scrutatoribus ad proficiendum in via salutis eterne occasionem obtuli [...] et mihimetipsi in dies memorie vivacis retentiam perdenti quemdam thezaurum ad modum chaos confusi secundum multiformium ex eo formabilium circa scibilia spiritualia cuiuslibet legis rationalis tractatuum seminaria continentem confeci in laudem scientiarum domini et sine preiudicio sententie sanioris cuiuslibet me peritioris philosophi, iuriste aut theologi sub correctione quoque horum et quorumlibet aliorum veritatem theologicam sapienter zelantium". 
de las compilaciones justinianeas, canónicas y feudales, sino de una derivación de principios teológicos que llegan hasta cuestiones jurídicas. En este sentido, el punto de partida es similar al de Llull. Al igual que Sibiuda, busca simplificar el Arte del Doctor Iluminado, pero su principal cometido es el de reformar el pensamiento de Llull para hacerlo accesible para la escolástica peripatética. Sibiuda es -siguiendo el léxico de nuestros contemporáneos- el encargado de "urbanizar" a Llull, mientras que a Heymericus le corresponde la labor de adaptar y reintegrar el lulismo en los debates escolásticos del momento.

En Heymericus se encuentran fuentes e ideas eclécticas: por una parte, es un seguidor del albertismo y del lulismo, y se opone tanto al nominalismo como al tomismo. En este sentido cabe decir que su filosofía es neoaristotélica y luliana, y que sus obras resienten ambas influencias en casi igual proporción. Las bases filosóficas y teológicas son una combinación de la metafísica de Alberto Magno y de Llull, mientras que las derivaciones específicamente jurídicas son, por lo general, más lulianas.

Los profesores Calma e Imbach han escrito, con acierto, que el tema central del Colliget principiorum iuris naturalis [...] es una teoría metafísica del conocimiento que explica también los principios del derecho ${ }^{72}$. Hasta donde he podido alcanzar, esta obra da una explicación ontológica y epistemológica de todo el conocimiento, que empieza en Dios y acaba en el actuar humano. Como se ha podido ver antes, al comentar el pensamiento de Sibiuda, se encuentra también el tránsito de Dios hacia el hombre a través de la teología, la ontología y la ética.

Pero Heymericus de Campo añade una preocupación epistemológica. Le interesa englobar todo el saber del mundo, siguiendo y respetando las ideas de Llull, pero prescindiendo -como Sibiuda- del aparato nemotécnico del Arte. La epistemología de Heymericus se basa en el proyecto de coleccionar reglas y principios (Llull) para construir una ciencia universal mediante el estudio de la naturaleza (Aristóteles). Con ello pone las bases de una derivación de principios: por una parte, desde la filosofía natural llega hasta la ley natural y, por otra, desde el saber universal se deriva el saber jurídico.

Si los trabajos que se han realizado hasta ahora sobre Heymericus ponían el acento en la dimensión metafísica, hay que destacar que el manuscrito tiene también una importante proyección jurídica, ya que abre las puertas, no sólo a un posicionamiento conciliarista en el derecho canónico ${ }^{73}$ y en la teoría política (que queda fuera del ámbito de estudio del presente escrito), sino a una suerte de "lulismo jurídico" compatible con la filosofía peripatética.

Colliget principiorum iuris naturalis [...] tiene cuatro partes, de las cuales sólo la cuarta está específicamente dedicada a temas jurídicos. De ella, la primera distinción (ff. 254v- 256v) trata de cuestiones generales, y la segunda de los principios y los corolarios de la ley natural (ff. 256v-265v), la tercera explica la correspondencia entre los principios de la ley natural y el derecho humano (po-

${ }^{72}$ Véase Calma, D. - ImBaCH, R., Les notes marginales de Nicolas de Cuse au traité "Colliget principiorum" d'Heymeric de Campo, en ReInHARDT, K. (editor), Heymericus de Campo. Philosophie und Theologie im 15. Jahrhundert, cit. (n. 66), p. 20.

${ }^{73}$ Colliget principiorum iuris naturalis, "Codex Cusanus" 106, f. 272 r. 
sitivo) (ff. 265v-272r) y la breve cuarta distinción está destinada al estudio del derecho canónico (f. 272r-273v).

En la cuarta distinción se encuentra el desarrollo singular de una visión luliana del derecho que quiere buscar parentesco con la obra de Aristóteles ${ }^{74}$. El lenguaje que usa Heymericus de Campo es sincrético, tomando préstamos de uno y de otro. Destaca sobre todo la estructura de los principios lulianos del Liber principiorum iuris, que quiere casar con el decálogo de Moisés: de esta forma se muestra la racionalidad del derecho divino a través de los principios teológicos que permiten llegar a la ley natural.

Heymericus sitúa asimismo el saber jurídico como un derivado del saber filosófico-teológico, aunque no está interesado en el estudio del derecho en tanto que saber sustantivo. Su obra es una gran síntesis de los saberes naturales (que abarcan desde la teología hasta la ley natural, pasando por la filosofía), que armoniza a Aristóteles con Llull. En este sentido, es un producto tardío de la escolástica centroeuropea, pero también es una de las bases del enciclopedismo moderno.

Precisamente, uno de los puntos donde Heymericus resulta un vínculo más claro entre Llull y los enciclopedistas lulistas del XVII (Alsted, Leibniz, Kircher, etc.) es en su valoración de algunos aspectos formales del Arte. Por ejemplo, mediante un alphabetum iuris naturalis ${ }^{75}$ que parece más un símbolo que un elemento imprescindible en su argumentación, Heymericus allana el camino hacia el iusnaturalismo racionalista y hacia el establecimiento de una scientia iuris basada en unos principios filosófico-teológicos de carácter racional.

\section{Bernard Lavinheta (1462-¿?).}

En la generación que nace después de la muerte de Heymericus, ya plenamente comprometida con las ideas del humanismo, brilla el franciscano Bernard Lavinheta. Este autor vive a caballo entre los siglos XV y XVI, y es un importantísimo sintetizador, expositor y revisor de la obra de Llull. Es profesor en Salamanca y en París, hecho que le facilita conocer las diferentes corrientes del lulismo europeo: está al corriente de la interpretación lógica y escotista que se defiende en una parte de los reinos hispánicos ${ }^{76}$, pero también de la lectura espiritualista de Lefevre d'Étaples y Charles de Bouvelles ${ }^{77}$.

\footnotetext{
${ }^{74}$ Colliget principiorum iuris naturalis, "Codex Cusanus" 106, f. 258v: "Quia ordo non habet esse perfectum nisi in ternario principii, medii et finis, et iustitia sit facultas ordinativa, ideo unitas et binarius et quodlibet expers ordinis excedunt a lege iustitie naturalis". Nótese, que en el ejemplo anterior existe una mezcla de la doctrina luliana y de la filosofía aristotélica (teoría de los correlativos, división entre principio, medio y fin).

${ }^{75}$ Colliget principiorum iuris naturalis, "Codex Cusanus" 106, f. 255v. No me parece que este alfabeto esté vinculado directamente a las nueve "flores" del árbol luliano ni que tenga una fuerza tan relevante en Heymericus como en Llull. Sin embargo, resulta innegable que este alfabeto procede del Arte luliano y que comparte con él algunas de sus definiciones.

${ }^{76}$ Sobre la enseñanza del lulismo, véase: RAMIS BARCELOO, R., Un esbozo cartográfico del lulismo universitario y escolar en los Reinos Hispánicos, en Cuadernos del Instituto Antonio de Nebrija de Estudios sobre la Universidad, 15 (2012) 1, p. 69.

${ }^{77}$ Véase Luinarès, A., Le lullisme de Lèfevre d'Etaples et ses amis humanistes, en Colloque International de Tours (XIV stage) (Paris, 1973), pp. 127-136; y PereIRA, M., Bernardo Lavin-
} 
El círculo parisino, a diferencia del platonismo de Sibiuda, intenta conciliar el aristotelismo, el lulismo, la mística y la devotio moderna ${ }^{78}$. En este aristotelismo lulista hunden sus raíces algunas de las manifestaciones del aristotelismo antiescolástico del humanismo francés del XVI, tal como la de Petrus Ramus. Lavinheta une a todas estas influencias su formación escoto-agustiniana, y es el autor que sirve de transición entre el lulismo del XV y el del XVI, pues es capaz de presentar el Arte de Llull de forma ordenada y sistemática para todos los saberes.

Por el hecho de subrayar las tendencias lógicas, la obra de Lavinheta presenta el Arte de Llull como un instrumento general para conocer de forma necesaria la verdad y crear así una ciencia universal. En Lavinheta, pese a las implicaciones metafísicas de su obra, se encuentra la base tanto de la visión instrumental del Arte del XVII como del enciclopedismo lulista-ramista. Estas dos corrientes son la cara de una misma moneda, que comprende el Arte desde una posición estrictamente instrumental y sin tener en cuenta las implicaciones ontológicas y teológicas del mismo. Sólo desde Leibniz hasta Salzinger se recupera progresivamente el espíritu metafísico luliano ${ }^{79}$, soslayado durante buena parte de los siglos XVI y XVII.

El objetivo de Lavinheta es el de elaborar una síntesis luliana capaz de mostrar una ciencia universal de los principios primordiales del saber ${ }^{80}$. A través de ellos se podrían demostrar, a su vez, los principios particulares de las diversas ciencias, entre ellas, la del derecho. En este sentido, Lavinheta preconiza el racionalismo jurídico, pues se abre a las novedades intelectuales del saber y las integra en un humanismo ejemplarista. Dicho humanismo sacrifica la mística en pos de un carácter lógico-aristotélico, que puede presentar de forma atractiva a Llull tanto a los escolásticos como a los humanistas.

Esta visión sistemática de la obra de Llull le permite conectar no sólo con diferentes ambientes intelectuales, sino también mostrar la aplicación del Arte luliano a los diferentes saberes. Por ese motivo, mientras la obra de Heymericus de Campo tiene sólo una influencia entre filósofos y teólogos, la obra de Lavinheta, gracias a su periplo vital y a sus amistades repartidas en diferentes lugares de Europa, llega también a los humanistas franceses e italianos, así como también a juristas, médicos y astrónomos.

heta e la diffusione del Lullismo a Parigi nei primi anni del '500', en Interpres. Rivista di Studi Quattrocenteschi, 5 (1984), pp. 242-265.

${ }^{78}$ Véase VICTOR, J., Jacques Lefêre d'Étaples, Charles de Bovelles and Bernardo de Lavinheta: The Revival of Lullism at Paris, 1499-1516, Renaissance Quartely, 28, (1975), pp. 504-534.

${ }^{79}$ En la obra de Lavinheta, autor formado en el escotismo, no se puede encontrar en absoluto una visión antimetafísica. Al contrario, en muchos ámbitos, y también en el del derecho, se favorece una interpretación ejemplarista del Arte, más consonante con el período cuaternario de Llull. Sin embargo, la lectura que se hizo de su obra en el XVII dio lugar a una visión más lógico-mnemotécnica. Véase PlatzeCK, E. W., "Introducción" a Explanatio compendiosaque applicatio Artis Raymundi Lulli (Hildesheim, Gerstenberg, 1977), pp. i-xx, quien indica que Lavinheta al probar por razones necesarias la verdad de la fe cristiana, muestra también la importancia del Arte para la teología.

${ }^{80}$ Un buen resumen de la obra puede verse en BÁEZ RuBí, L., Mnemosine Novohispánica: Retórica e Imágenes en el siglo XVI (México, UNAM, 2005), pp. 103-117. 
Según Elías de Tejada ${ }^{81}$, a través de su Practica compendiosa artis Raymundi Lulii, Lavinheta lleva a cabo importantes innovaciones en la metodología jurídica ${ }^{82}$. En efecto, en Lavinheta se encuentran tanto la exposición del Ars iuris como dos ideas fundamentales que conectan el discurso luliano con el del momento: en primer lugar, la necesidad de sistematizar el saber jurídico, ordenando las leyes de la época reduciéndolas al Arte en base a la ley natural ${ }^{83}$; en segundo lugar, el establecimiento de unos principia primitiva iuris.

Dichos principios son: ius divinum, ius naturale, ius gentium y ius positivum. El ius divinum se halla por definición de la mayoridad, minoridad y concordancia existente entre Dios y el hombre. El ius naturale consiste en la necesaria definición de razón, definición, concordancia etc. El ius gentium se encuentra por definición de la concordancia existente entre el hombre y el hombre. Finalmente, el ius positivum consiste en la voluntaria razón del hombre que lo busca ${ }^{84}$. Esta interpretación, que incluye al ius gentium resulta atractiva también para los juristas del momento ${ }^{85}$.

Lavinheta realiza una síntesis de las dos primeras versiones del Arte dedicadas al derecho (Liber principiorum iuris y Ars iuris) con la visión más gráfica y pedagógica del Arbor scientiae ${ }^{86}$. Lavinheta prefiere la visión ejemplarista de libros de la época cuaternaria ${ }^{87}$, aunque es capaz de armonizarla sincréticamente con el aristotelismo y con las doctrinas del iusnaturalismo marcadamente racionalista que va abriéndose paso en esa época.

Así, tal y como se ha visto en la explicación del Ars $_{\text {iuris }}{ }^{88}$, Lavinheta simboliza su esquema con una figura muy parecida a la de esta obra: A (Deus), B (Ius naturale), C (Actor), D (Ius positivum), E (Reus), F (Anima actoris), G (Corpus actoris), H (Corpus rei), I (Anima rei). La figura representa dos cuadrados secantes ("duo magni quadranti secantes se aequaliter in angulis" ${ }^{9}$ ) de forma que las ocho puntas representan las ocho letras. En el centro está A (Ius divinum). En el círculo inscrito entre los cuadrados se encuentran doce dignidades: iustitia, donnatio, bonitas, magnitudo, eternitas, potestas, sapientia, voluntas, virtus, veritas, gloria y largitas $^{90}$.

\footnotetext{
${ }^{81}$ Sobre la modernidad de Lavinheta, véase ElíAS DE TEJADA, F., Historia del pensamiento político catalán, cit. (n. 2), II, p. 172.

${ }^{82}$ Bernhardi de Lavinheta Opera omnia: quibus tradidit artis Raymundi Lullii compendiosam explicationem (Lugundi, Lazari Zetzneri, 1612), pp. 520-539 y las cuestiones respectivas se encuentran en las páginas 640-649.

${ }^{83}$ Ibíd., p. 536 "[...] Habito modo practicandi figuram iuris et investigandi jus cuiuslibet de modo reducendi omnia jura positiva ad arte [...["

${ }^{84}$ Bernhardi de Lavinheta Opera omnia, cit. (n. 82), p. 521.

${ }^{85}$ Véase CARPINTERo, Francisco, La ley natural. Historia de un concepto controvertido (Madrid, Encuentro, 2008), p. 250.

${ }^{86}$ Parece casi seguro que Lavinheta participó junto a Josse Bade en la edición del Arbor scientiae venerabilis et celitus Illuminati Patris Raymundi Lullii Maioricensis (Lyon, Josse Bade, 1515).

${ }^{87}$ Bernhardi de Lavinheta Opera omnia, cit. (n. 82), pp. 527 y ss.

${ }^{88}$ Ars iuris, cit. (n. 47), primer folio, s. f.

${ }^{89}$ Bernhardi de Lavinheta Opera omnia, cit. (n. 82), p. 532.

${ }^{90}$ Ibíd., p. 532.
} 
Con ello, Lavinheta hace una reforma en toda regla de la concepción luliana del derecho, pues la figura deviene una síntesis de la obra de Llull con una visión algo menos ingenua que la de éste, que integra a su vez otras dignidades $\mathrm{y}$, sobre todo, que basa su interpretación en la diferencia entre la ley natural y el derecho positivo. Permanece, sin duda, el ejemplarismo de Llull y la visión procesal, pero la figura es más rica y, sobre todo, más atractiva a los ojos de sus contemporáneos.

Dedica varias páginas a las cuestiones acerca del derecho, en las que, entre otros puntos, se pregunta, siguiendo a Llull, si el derecho se debe buscar más por razón de la materia o de la forma y si la injuria es lo opuesto del derecho. Tales preguntas desembocan en la cuestión más general: el modo de obtener un derecho universal a partir de los derechos particulares ${ }^{91}$. Su concepción concluye con algunas cuestiones sobre la materia y la forma en el derecho natural ${ }^{92}$ y el positivo, así como con algunas cuestiones de derecho canónico ${ }^{93}$, que sirven para mostrar la relevancia del arte de Llull para resolver los problemas jurídicos.

Es necesario profundizar en el análisis de la obra de Lavinheta para observar los desgarros que se producen al comentar la jurisprudentia luliana. La mayor tensión se produce entre una comprensión ejemplarista de la ley natural (fundamentada en las dignidades divinas y propia de la época cuaternaria) y la voluntad de Lavinheta de fundar una "ciencia luliana" del derecho, basada en la combinatoria (los principios del derecho). En la obra de este sabio franciscano se encuentra una síntesis aparentemente indolora entre el ideal agustiniano y la presentación enciclopédica del Arte como base para todos los saberes, partiendo de un aristotelismo humanista.

Puede decirse que, en el ámbito del derecho, Lavinheta representa un momento clave entre el lulismo medieval y el moderno. Este autor es capaz de presentar una exposición ordenada y racional del derecho luliano, capaz de interesar a los teólogos, a los filósofos y a los juristas. Si Sibiuda y Heymericus habían adoptado algunas ideas lulianas para sus sistemas, adaptándolas a las necesidades del momento, en la obra de Lavinheta se encuentra ya una exposición clara del pensamiento jurídico luliano, sin renunciar a la dimensión más metafísica del mismo, pero capaz de influir directamente en los teóricos del derecho.

Puede decirse, por lo tanto, que su relevancia se basa en dos dimensiones: la primera, su obra pone las bases para la concepción enciclopédica de las ciencias de los siglos posteriores ${ }^{94}$, y la segunda, es capaz de presentar de forma organizada (y de reformular) el pensamiento jurídico de Llull, situándolo en el marco del iusnaturalismo racionalista y en el contexto de la emergencia de la scientia iuris.

${ }^{91}$ Ibíd., p. 645.

${ }^{92}$ Ibíd., p. 649. "Jus naturale esse communius ratione conditionum formae, quam materiae: accidit autem quandoque in particulari ipsum jus esse generalius ratione materiae, quam ratione formae".

${ }^{93}$ Ibíd., pp. 649-650.

${ }^{94}$ Sobre la proyección de la obra de Lavinheta, véase: Angelini, A., Metodo ed Enciclopedia nel cinquecento francese, I: Il pensiero di Ramo all'origine dell'enciclopedismo moderno (Firenze, Leo S. Olschki, 2008), pp. 239-283. 


\section{Pierre de Grégoire (1540-1597).}

Si durante el siglo XV sólo se encuentran juristas interesados en el Arte de Llull y teólogos preocupados por la ley natural, en el siglo XVI se hallan ya los frutos jurídicos de la labor teológica llevada a cabo, entre otros, por Sibiuda, Heymericus de Campo y Lavinheta.

Uno de los juristas más destacados del XVI es el tolosano Pierre de Grégoire, un autor -como tantos otros de su época- influido por Jean Bodin ${ }^{95}$. Escribe muchas obras, entre las que destaca Syntaxis artis ${ }^{96}$, cuya segunda parte Syntagma iuris univers $i^{97}$ (publicada de forma independiente) está dedicada al derecho. El interés de Grégoire se encuentra en su empeño de escribir una nueva Ars Mag$n a$, que quiere ser una ciencia universal con resabios herméticos de Lavinheta y Agrippa $^{98}$. La referencia a Llull es más implícita que explícita a lo largo de toda la obra, aunque resulta un paso definitivo para construir una enciclopedia de todos los saberes ${ }^{99}$.

Antes de escribir Syntagma iuris universi -tal vez su obra jurídica más ambiciosa-, había dado a la imprenta De iuris arte, methodo et praeceptis ${ }^{100}$, Universi iuris methodus parva et compendiosa ${ }^{101}$, Praeludia optimi iurisconsulti probique magistratos ${ }^{102}$, tres obras que se encuentran cercanas al pensamiento humanista que pretende sistematizar el derecho a través de un método universal. A diferencia de François Connan, Joachim Hopper u otros juristas humanistas de la misma época ${ }^{103}$, en Pierre de Grégoire se encuentra un planteamiento mucho más luliano

${ }^{95}$ La clásica obra sobre Grégoire es Collot, C., L'École Doctrinale de Droit Public de Pontà-Mousson (Pierre Grégoire de Toulouse et Guillaume Barclay) à la fin du XVIe siècle (Paris, R. Pichon et R. Durand-Auzias, 1965). Sobre Bodin y la influencia humanista en Grégoire, véase: JaCobsen, M. C., Jean Bodin et le dilemme de la philosophie politique moderne (Copenhague, Copenhague Museum Tusculanum, 2000), pp. 95 y ss.

${ }^{96}$ Syntaxeon [sintaxis] artis mirabilis in libros septem digeste, per quas de omni re proposita multis et prope infinitis rationibus disputari aut tractari, omniumque summaria cognitio haberi potest (Lugduni, 1583-87). En esta obra, Grégoire muestra interés también por el lulismo hermético y alquímico. Véase el lib. 37, p. 474.

${ }^{97}$ Syntagma iuris universi, atque legum pene omnium gentium et rerum publicarum praecipuarum in tres partes digestum (Francoforti ad Moenum, Petri Ficheri, 1591).

${ }^{98}$ Sigue siendo imprescindible Rossi, P., Clavis universalis. Arti mnemoniche e logica combinatoria de Lullo a Leibniz (Milano-Napoli, Ricardo Ricciardi, 1960), pp. 57-59.

${ }^{99}$ Commentaria in Prolegomena Syntaxeon Mirabilis Artis (Coloniae, Lazari Zetzneri, 1600), pp. 16-17 (segunda numeración): "Sequitur deinde illud quod est confusionis mentis et indispositarum cogitationum coordinatio, in quo latet tota artis nostrae methodus: docet enim omnium praeceptorum quae diffunduntur per res, et scientias, artesque particulares, in certa capita reductionem ordinatam, ex cuius cognitione postea mens dispensat ordinate et inconfuse propria unicuique negotio oblato, disputando, tractando, consulendo, probando, vel refellendo, vel docendo, vel eligendo; haec enim in omnibus locum habet [...] Qua ratione et nos in hace arte magna ne quid deesset particularium finium, singularium scientiarum, veluti quoddam epitome contextuimus, ut Dei beneficio et nostro medio, quicunque nostras habuerit locubrationes, nullis aliis libris, vel certe paucissimis egeat ad scientiarum encyclopaediam addiscendam".

${ }^{100}$ De iuris arte, methodo et praeceptis (Lugduni, Antonio Grifio, 1580).

${ }^{101}$ Universi iuris methodus parva et compendiosa (Lugduni, Antonio Grifio, 1582).

${ }^{102}$ Praeludia optimi iurisconsulti probique magistratus (Lugduni, Antonio Grifio, 1583).

${ }^{103}$ Para una contextualización de la obra de Pierre de Grégoire, véase: Rodríguez PuERTo, 
de Ars universalis, aunque, como se verá, con algunas diferencias notables con el Doctor Iluminado.

Syntagma iuris universi es una obra vastísima que quiere ser una sistematización de todo el derecho (civil y canónico). Pierre de Grégoire es uno de los docentes más afamados de su época ${ }^{104}$ y ha sido considerado habitualmente como uno de los primeros sistematizadores del saber jurídico. Queda por estudiar la influencia implícita de Llull en esta obra, ya que -hasta donde alcanzo a ver- no hay ninguna referencia explícita que lo atestigüe. Se encuentran, curiosamente, referencias a Llull en obras y contextos no jurídicos ${ }^{105}$.

El conjunto de la obra de Grégoire resulta un verdadero caos expositivo, donde se mezclan elementos heterogéneos de la más diversa procedencia y no se puede llegar a hablar, en puridad, de un seguimiento fidedigno de las ideas de Llull, sino una mezcla de "lulismo jurídico" con el estudio de las materias propias del derecho civil y canónico. Su iusnaturalismo no es estrictamente luliano, sino más bien de corte agustiniano o ciceroniano ${ }^{106}$, aunque sí lo es su ideal de saber universal y, como parte del mismo, la scientia iuris.

El pensamiento de Grégoire pone de relieve una enorme erudición y un notable eclecticismo. Integra también ideas de autores platónicos y ciceronianos, pero su concepción global se muestra asimismo muy próxima al pensamiento de Ramon Llull. Gregórie se diferencia de tantos otros juristas de la época que quieren reducir todo el derecho a un arte ${ }^{107}$, pues para él -igual que para Llull- el derecho es sólo una parte de una aspiración global al saber ${ }^{108}$.

A diferencia de Apel, Bolognetus y otros teóricos del derecho del siglo XVI, Pierre de Grégoire tiene una notable inclinación hacia la epistemología, y cree que se puede llegar al conocimiento de todas las cosas a partir del conocimiento general $^{109}$. Sin embargo, Grégoire entiende que el saber es relativamente acotado: no puede establecerse una tópica cerrada (siguiendo a Cicerón) ni tampoco una técnica combinatoria ${ }^{110}$, tal y como propugna Llull.

La influencia luliana es fundamental en tres puntos que caracterizan tanto a

M. J., La Modernidad discutida, Jurisprudencia frente a iusnaturalismo en el siglo XVI (Cádiz, Servicio de Publicaciones de la Universidad de Cádiz, 1999).

${ }^{104}$ El lugar de Grégoire en la jurisprudencia de su época puede verse en GILLES, H., La carrière méridionale de Pierre Grégoire de Toulouse, en GILLES, H., Mélanges offerts à Paul Couzinet (Toulouse, Presses Universitaires de Toulouse, 1974), pp. 263-327.

105 Syntaxeon artis mirabilis, lib. II, p. 851. Véase también De Republica libri sex et viginti: in duos tomos distincti (Lugduni, 1596), I, lib. 13, p. 1015.

${ }^{106}$ De iuris arte, cap. III, pp. 47 y ss. Véase también Syntagma iuris universi, pars II, p. 88.

${ }^{107}$ Según la historiografía clásica, el primer jurista que quiso reducir todo el derecho a un arte fue Sebastian Derrer, aunque muy alejado de la pretensión de ciencia universal que puede encontrarse en las obras de Grégoire. Véase Stinzing, R., Geschichte der deutschen Rechtwissenschaft (München, Oldenburg, 1880-1884), II, pp. 256 ss.; y también CARPINTERO, F., "Mos Italicus", "mos Gallicus" y el humanismo racionalista. Una contribución a la historia de la metodología jurídica, en Ius commune, 6 (1977), p. 158.

${ }^{108}$ Véase Rodríguez Puerto, M. J., La Modernidad discutida, cit. (n. 103), pp. 225 y 287.

${ }^{109}$ Syntaxeon artis mirabilis, lib. II., pp. 7-10.

${ }^{110}$ Sobre estas diferencias, véase Rodríguez Puerto, M. J., La Modernidad discutida, cit. (n. 103), pp. 351-352. 
Syntagma iuris universi como a De iuris arte y los Prealudia. En primer lugar, la concepción de que todo el derecho procede de Dios ${ }^{111}$, aunque no en el sentido emanantista del período cuaternario de Llull ${ }^{112}$, sino más bien en el platonizante propio del Renacimiento. De todas formas, Grégoire reconoce explícitamente la procedencia divina del derecho, una manera implícita de subordinarlo a la teología, tal y como hace Llull en el Liber principiorum iuris y en el Ars iuris. Manuel Rodríguez Puerto nota, con acierto, ciertos desgarros ${ }^{113}$ entre esta concepción teológica y la descripción "prudencial” (en cierta manera, ciceroniana) que hace el jurista tolosano de la "ciencia del derecho". En efecto, el eclecticismo de Grégoire busca reducir todo el derecho al arte, pero sin que éste sea algo cerrado: un arte abierto, que quiere ser fiel a Llull sin dejar de lado el platonismo y la influencia ciceroniana.

En segundo lugar, otra destacada huella se halla en la relevancia que tienen las reglas ${ }^{114}$ como mecanismo de este arte, un punto en el que nuevamente se acerca al Doctor Iluminado. Pero, en fin, el tema en el que el jurista tolosano se acerca más a Llull es en el de las razones ${ }^{115}$ : para el jurista tolosano, no hay una solución directa expresada en la casuística, sino una ponderación de razones para hallar la solución.

Grégoire es un profesor de Leyes que conoce perfectamente la tradición romanística y canónica, así como los distintos ordenamientos de su época. Pese a tener una aspiración a trascender los límites del derecho, el jurista tolosano -para teorizar sobre el derecho- toma la casuística y los derechos que le resultan familiares ${ }^{116}$. Por esa razón, pese a compartir con Llull una idea de scientia iuris que forma parte de una scientia generalis, procede por “inducción” de los derechos, mientras que Llull lo hace por deducción filosófico-teológica de los principios del Arte aplicado al derecho ${ }^{117}$.

Llull no es partidario de un conocimiento ni tópico ni casuístico, aunque sus obras muestran la aplicación del Arte a los problemas jurídicos. Siguiendo la clasificación de Viehweg ${ }^{118}$ debería considerarse que Llull es un autor no estrictamente axiomático, aunque si capaz de crear una "combinatoria" jurídica. Grégoire no es tan categórico como Llull, pues considera que el derecho no es un sistema cerrado, sino que existen razones prudenciales y una necesidad de ponderación.

Finalmente, en tercer lugar, existe una clara coincidencia entre Ramon Llull y Pierre de Grégoire en su concepción del ars iuris como base de la scientia iuris.

${ }^{111}$ Praeludia optimi iurisconsulti, lib. V. p. 491.

${ }^{112}$ Véase Ramis Barceló, R., "Estudio Preliminar", cit. (n. 5), pp. 24-32.

${ }^{113}$ Véase Rodríguez Puerto, M. J., La Modernidad discutida, cit. (n. 103), p. 348.

${ }^{114}$ De iuris arte, passim.

${ }^{115}$ De iuris arte, cap. 18, p. 359. "Cur autem expedire videatur, ius in artem redigi, et de praecepta et costitui, subeunt metem variae rationes, quarum aliquas tantum oriferam, quae universo omnique iuri conveniant: nec repetam illas, que in iure positiuo traditae sunt, quae hunc in locum quoque transferri possunt".

${ }^{116}$ Sobre la pugna entre la tradición romanística y la necesidad de un método universal, véase: BirocchI, I., Alla recerca dell'ordine. Fonti e cultura giuridica nell'età moderna (Torino, Giappichelli, 2002), pp. 19-49.

${ }^{117}$ Véase Ramis Barceló, R., "Estudio Preliminar", cit. (n. 5), p. 57.

${ }^{118}$ Véase VIEHWEG, T., Tópica y jurisprudencia (Madrid, Taurus, 1986), pp. 116-118. 
Para otros teóricos del arte del derecho ${ }^{119}$, como Hopper o Connan, el arte es capaz de englobar todo el derecho y sirve para resolver cuestiones jurídicas ${ }^{120}$. Para Grégoire, el ars iuris es sólo un mero instrumento para conocer la esencia del derecho.

En este sentido, cabe decir que para Grégoire existe una tajante distinción entre el derecho como manifestación social (ius) y como saber (ars iuris) ${ }^{121}$. Considera que la esencia del derecho no puede ser conocida si no es a través de un método o arte por el jurista, algo que Llull también sostiene. Curiosamente, el jurista tolosano parece coincidir más con las dos últimas obras de Llull, pertenecientes al período ternario ${ }^{122}$, en el que el emanantismo se sustituye paulatinamente por la combinatoria. No se sabe hasta qué punto Grégoire llega a tener acceso a Ars de iure y Ars brevis de inventione iuris, pero en su obra se detecta un reforzamiento de la técnica combinatoria, propia de estas obras lulianas de madurez.

A diferencia de otros juristas de su época, que busca algunos modestos préstamos de la filología o de la historia ${ }^{123}$, la concepción del derecho de Grégoire exige una apertura del jurista hacia las demás disciplinas (teología, filosofía, astronomía, retórica...) En este sentido puede decirse que la visión luliana le resulta útil para robustecer los fundamentos teóricos del derecho, en una época en la que la scientia iuris quiere discernir su método. Grégoire, como uno de los principales teóricos del derecho del XVI, adapta las ideas jurídicas de Llull a su visión sistemática, las completa y las revisa.

Grégoire es el primer teórico del derecho que usa los modelos jurídicos lu$\operatorname{lianos}^{124}$, pero su obra es muy caótica y acaba mezclando cuestiones de derecho sustantivo con problemas teóricos. Tampoco acaba de decidirse por una visión prudencial, tópica o por la propia de la combinatoria luliana. Sin embargo, pone las bases de la enciclopedia de todos los saberes ${ }^{125}$, así como del método universal para la scientia iuris, un paso fundamental para el establecimiento de un "sistema jurídico" racional que daría sus frutos en los siglos siguientes ${ }^{126}$.

\footnotetext{
${ }^{119}$ Véase la explicación general de la jurisprudencia del XVI en Piano Mortari, V., Diritto, logica, metodo nel secolo XVI (Napoli, Jovene, 1978), pp. 120 ss.

${ }^{120}$ Véase JACOBSEn, M. C., Jean Bodin et le dilemme de la philosophie politique moderne, cit. (n. 95), pp. 95-98.

${ }^{121}$ Puede verse la explicación de Rodríguez Puerto, M. J., La Modernidad discutida, cit. (n. 103), p. 349.

${ }^{122}$ Véase Ramis Barceló, R., "Estudio Preliminar”, cit. (n. 5), pp. 34-37.

${ }^{123}$ Véase, por ejemplo, para el caso de Budé: Piano Mortari, V., Diritto, logica, metodo, cit. (n. 119), p. 321-345.

${ }^{124}$ Así lo entiende también VAsoli, C., Profezia e ragione. Studi sulla cultura del Cinquecento e del Seicento (Napoli, Morano, 1974), pp. 663-664.

${ }^{125}$ Para la proyección de Grégoire en los siglos sucesivos, véase: Angelini, A., Metodo ed Enciclopedia nel cinquecento francese, cit. (n. 94); y VAsOLI, C., Profezia e ragione, cit. (n. 124), pp. 839-842 y 891-894.

${ }^{126}$ WIEACKER, Franz, Humanismus und Rezeption, en Rechtslehrer der neueren deutschen Privatrechtsgeschichte (Gottingen, Vandenhoeck und Ruprecht, 1959), pp. 85 ss., considera que la labor de los teorizadores del XVI fue un fracaso por no tener en cuenta el derecho sustantivo. Sin embargo, los esfuerzos de teorización de autores como Pierre de Grégoire son la base del systema iuris de los siglos posteriores.
} 
La influencia de las obras jurídicas de Llull llega a ser, gracias a los autores que aquí se han comentado, mucho más acusada en los siglos XVII y XVIII. Después de Grégoire, y tal vez mediante su influencia, otros juristas como Giulio Pace, Leibniz o eruditos como Athanasius Kircher usaron las ideas jurídicas de Llull para sus propios proyectos intelectuales. Asimismo, el ramismo converge con el lulismo a finales del XVI, y sus principales consecuencias jurídicas deben estudiarse ya en el marco del siglo XVII.

\section{CONClusiones}

En las páginas precedentes se ha intentado explicar la influencia de las ideas jurídicas de Ramon Llull en los siglos XV y XVI. Se trata, como se ha anunciado al principio, de una tentativa de síntesis de un tema inexplorado. De Sibiuda a Grégoire hay numerosas diferencias, pero todos los autores que se han visto en el artículo tienen en común la combinación del humanismo con el lulismo. De aquí que teóricos como Giulio Pace, que vivieron más en el XVI que en el XVII deban estudiarse ya en otro contexto, pues en su obra aparecen también rasgos ramistas, que deben examinarse en un marco intelectual diferente.

De lo expuesto hasta aquí se desprenden algunas conclusiones. La primera de ellas es que durante los siglos XIV y XV hay un desencuentro entre los juristas y el pensamiento jurídico luliano: existen juristas interesados en el Arte, y teólogos y filósofos preocupados por el derecho. La falta de una obra jurídica de inspiración luliana durante estos dos siglos se debe a dos factores: el primero de ellos, la falta de estudio homogéneo del Arte de Llull y, el segundo, la tendencia casuística y prudencial del ius commune.

La segunda idea es que el lulismo tardomedieval tiene que abrirse paso en el marco de una nueva concepción del hombre y de la naturaleza. De ahí la necesidad de adaptar y normalizar el lulismo para los lectores de los albores del Renacimiento. Esa es la labor de Sibiuda, que adapta a Llull a la tendencia intelectual del momento. En Sibiuda se encuentra una exposición del iusnaturalismo luliano en la que falta el Arte como instrumento. El autor del Liber nature sive creaturarum se muestra deliberadamente platónico y ejemplarista, mostrando una gran afinidad con el Llull de la época cuaternaria. El ejemplarismo de Sibiuda permite un reflejo directo de Dios en la naturaleza creada y, por supuesto, en el hombre. La dignificación del hombre como punto álgido creación divina permite la fundamentación de un derecho y un deber en la naturaleza y por naturaleza.

La tercera idea es que el lulismo del XV tiene que ser adaptado tanto para el estudioso de las diferentes ciencias, como para la exposición escolar. Heymericus de Campo representa un paso importante en el establecimiento de un estudio de los principios filosófico-teológicos del derecho. Con la obra de Lavinheta se culmina esa labor expositiva y se llega a una síntesis ordenada de todos los saberes lulianos, entre ellos, el saber jurídico. Después de esta labor de sistematización y de adaptación al humus cultural, queda despejado el camino para el estudio de un saber jurídico luliano.

La cuarta de las conclusiones es que, gracias a una exposición general de las 
ideas de Llull, cada una de las disciplinas puede acudir a las ideas del Doctor Iluminado para adaptarlas a las necesidades. Sin duda, el debate teórico-jurídico en el siglo XVI es el dilema entre, por un lado, una visión casuística o prudencial del derecho, y por otro, la construcción de un sistema jurídico racional. Llull es un aliado de quienes quieren ordenar el sistema jurídico a través de las coordenadas del racionalismo jurídico, establecidas por Lavinheta y solidificadas por Grégoire.

La quinta idea es que en el siglo XVI el interés de los juristas (aunque sí el de los filósofos y teólogos) no se encuentra en la esencia de la ley natural, sino en la construcción de una scientia iuris. Llull permite superar la concepción prudencial y casuística del derecho y preparar los caminos para el establecimiento de un ars iuris dispuesto para la sistematización de los principios jurídicos. La obra de Pierre de Grégoire es una manifestación clara de esta voluntad sistemática.

La sexta conclusión que se extrae del itinerario histórico propuesto es que desde el XV hasta finales del XVI se asiste, a través del lulismo, al retorno del platonismo y el aristotelismo. Con el platonismo agustiniano, lo más relevante en términos es la relación entre el hombre y Dios a través de la justicia y el descubrimiento de la ley natural. El aristotelismo pone el énfasis en la búsqueda material de la ley natural y de la justicia. Puede decirse que el recorrido histórico abarca desde una concepción teológica de la ley natural y de la justicia, que es capaz de poner el Arte entre paréntesis, hasta una visión que se centra en el Arte como forma absolutamente necesaria para investigar la ley natural y la justicia.

La última de las conclusiones es que las objeciones que muestra Grégoire a algunas de las ideas de Llull ponen de manifiesto los propios límites del derecho como saber (así como sus dificultades para sistematizarlo). Asimismo, el hecho de que Grégoire no pueda aceptar por completo una visión sistemática y combinatoria del derecho, renunciando al carácter prudencial y casuístico, muestra también que el jurista humanista tiene grandes dificultades en considerar la aplicabilidad del propio sistema luliano. De ahí que, después del XVI, lo más importante no sea ahondar en las raíces del pensamiento luliano, sino reformar el Arte.

Ciertamente, el fracaso de los teóricos del derecho del XVI, expresado por Wieacker, no es una derrota del saber jurídico en el marco de las pujantes ciencias exactas y naturales, sino un momento de indefinición entre diferentes modelos para la construcción de un saber jurídico renovador. La presencia de Llull en el debate del XVI permite que su obra se reconsidere en el XVII bajo la perspectiva enciclopédica y combinatoria.

El carácter rígido del Arte de Llull aplicado al derecho permite poca adaptación al carácter fragmentario, casuístico y a veces alógico del derecho justinianeo o canónico. Sin embargo, el estudio de las obras lulianas supone en la época humanística un empujón definitivo para la construcción de la moderna scientia iuris, basada en un sistema jurídico ordenado y con cierta tendencia axiomática. La influencia de Llull en los autores del XVII es clave para entender el proceso de sistematización y racionalización del derecho desde Leibniz hasta la Pandectística del XIX, aunque estas cuestiones deberán tratarse ya en ulteriores trabajos. 


\section{BiBLIOGRAFÍA}

Andreu de Palma, Els sistemes jurídics i les idees jurídiques de Ramon Llull (Palma, Les Illes d'Or, 1936).

Angelini, A., Metodo ed Enciclopedia nel cinquecento francese, I: Il pensiero di Ramo all'origine dell'enciclopedismo moderno (Firenze, Leo S. Olschki, 2008).

Arbor scientiae venerabilis et celitus Illuminati Patris Raymundi Lullii Maioricensis (Lyon, Josse Bade, 1515).

Ars Iuris en Omnium scientiarum Magistri Beati Raymundi Lulli Doctoris Illuminati et Martyris Tertii Ordinis Seraphici Patris Sancti Francisci. Ars iuris et Arbor imperialis (Palma de Mallorca, Miquel Cerdà - Miquel Amorós, 1745).

Ars iuris illuminati doctoris Raymundi Lulii: que breuissima est \& artificio quodam intellectuali clauditur (Rome, Iacobum Mazochium, 1516).

Aureum sane opus in quo ea omnia breviter explicantur, qua scientiarum omnium parens Raymundus Lullus, tam in scientiarum arbore quam arte generali tradit (Augustæ, Micahaël Manger, 1589).

BÁEz Rubí, L., Mnemosine Novohispánica: Retórica e Imágenes en el siglo XVI (México, UNAM, 2005).

Batllori, M., El lul.lisme a Itàlia. Esbós de sintesi, El lul.lisme del Renaixement, en Batllori, M., Ramon Llull i el lul.lisme. Obra Completa (edición de Eulàlia Duran, València, Tres i Quatre, 1993), II.

Batllori, M., El lul.lisme del Renaixement, en Batllori, M., Ramon Llull i el lul.lisme. Obra Completa (edición de Eulàlia Duran, València, Tres i Quatre, 1993), II.

Batllori, M., Le lullisme de la Renaissance et du Baroque: Padoue et Rome, en Actes de XIème. Congrès International de Philosophie, 13 (Amsterdam-Louvain, 1953).

Bernhardi de Lavinheta Opera omnia: quibus tradidit artis Raymundi Lullii compendiosam explicationem (Lugundi, Lazari Zetzneri, 1612).

Bonner, A., The Art and Logic of Ramon Llull: A User's Guide (Leiden - Boston, Brill, 2007).

Calma, D. - Iмвасн, R., A Fifteenth-Century Metaphysical Treatise: Preliminary Remarks on the "Colliget principiorum" of Heymericus de Campo, en Przeglad Tomistyczny, 14 (2008).

Calma, D. - ImbaCh, R., Les notes marginales de Nicolas de Cuse au traité "Colliget principiorum" d'Heymeric de Campo, en ReInHARDT, K. (editor), Heymericus de Campo. Philosophie und Theologie im 15. Jahrhundert (Regensburg, Roderer, 2009).

Carpintero, F., "Mos Italicus", "mos Gallicus” y el humanismo racionalista. Una contribución a la historia de la metodología jurídica, en Ius commune, 6 (1977).

Carpintero, Francisco, La ley natural. Historia de un concepto controvertido (Madrid, Encuentro, 2008).

Collot, C., L'École Doctrinale de Droit Public de Pont-à-Mousson (Pierre Grégoire de Toulouse et Guillaume Barclay) à la fin du XVIe siècle (Paris, R. Pichon et R. Durand-Auzias, 1965).

Colomer, E., De la Edad Media al Renacimiento (Barcelona, Herder, 1975).

Cruz Hernández, M., El pensamiento de Ramon Llull (Madrid, Castalia, 1977).

Dionísıo, J., Literatura Franciscana no Leal Conselheiro de D. Duarte, en Lusitânia Sacra, XIII-XIV (2001-2002).

Domínguez, F. - GayÀ, J., "Life" en Raimundus Lullus. An Introduction to his Life, Works and Thought (Turnhout, Brepols, 2008). 
Don Juan Manuel, Obras Completas (ed. de J. M. Blecua, Madrid, Gredos, 1981).

Elías de Tejada, F., Historia del pensamiento político catalán (Sevilla, Ediciones Montejurra, 1963), II.

Gilles, H., La carrière méridionale de Pierre Grégoire de Toulouse, en GiLles, H., Mélanges offerts à Paul Couzinet (Toulouse, Presses Universitaires de Toulouse, 1974).

GonzÁlez Rodríguez, B., La tercera vía: la antropología política de Raimundo Sibiuda, en Res publica, 18 (2007).

Gregorius Tholosanus, Petrus, De iuris arte, methodo et praeceptis (Lugduni, Antonio Grifio, 1580).

Gregorius Tholosanus, Petrus, Praeludia optimi iurisconsulti probique magistratus (Lugduni, Antonio Grifio, 1583).

Gregorius Tholosanus, Petrus, Syntagma iuris universi, atque legum pene omnium gentium et rerum publicarum praecipuarum in tres partes digestum (Francoforti ad Moenum, Petri Ficheri, 1591).

Gregorius Tholosanus, Petrus, Syntaxeon [sintaxis] artis mirabilis in libros septem digeste, per quas de omni re proposita multis et prope infinitis rationibus disputari aut tractari, omniumque summaria cognitio haberi potest (Lugduni, 1583-87).

Gregorius Tholosanus, Petrus, Universi iuris methodus parva et compendiosa (Lugduni, Antonio Grifio, 1582).

Imbach, R. - Ladner, P., Heymericus de Campo. Opera selecta (Freiburg, Universitäts Verlag, 2001).

JACOBSEN, M. C., Jean Bodin et le dilemme de la philosophie politique moderne (Copenhague, Copenhague Museum Tusculanum, 2000).

Kamar, E., Projet de Raymond Lull "De acquisitione Terrae Sanctae". Introduction et édition critique du texte, Studia Orientalia Cristiana, 6 (1961).

Liber nature sive creaturarum. In quo tractatur specialiter de homine et de natura eius in quantum homo, et de his, que sunt ei necessaria ad cognoscendum seipsum et edeum: et omne debitum, ad quo homo tenetur, et obligatur tam deo quam proximo et in sacra pagina egregio professore (edición de F. Stegmüller, Stuttgart, Friedrich Frommann, 1966).

Llinarès, A., Le lullisme de Lèfevre d'Etaples et ses amis humanistes, en Colloque International de Tours (XIV stage) (Paris, 1973).

Llull, Ramon, Leal Conselheiro (edición crítica de M. H. Lopes de Castro, prefacio de A. Botelho, Lisboa, IN-CM, 1999).

LluLl, Ramon, Obres Essencials] (Barcelona, Selecta, 1957 y 1960).

Monserrat Quintana, A., La visión luliana del mundo del Derecho (Mallorca, IEB, 1987).

Muñoz de Baena y Simón, J. L., Llull, un ensayo de epistemología jurídica (Madrid, Universidad de Alcalá de Henares, 1988, tesis doctoral inédita).

Nova Edició de les Obres de Ramon Llull (1993), II.

Obres de Ramon Llull (1906-1914), II-VIII.

Pereira, M., Bernardo Lavinheta e la diffusione del Lullismo a Parigi nei primi anni del '500', en Interpres. Rivista di Studi Quattrocenteschi, 5 (1984).

Piano-Mortari, V., Diritto, logica, metodo nel secolo XVI (Napoli, Jovene, 1978).

Planas Rosselló, A. - Ramis Barceló, R., La Facultad de Leyes y Cánones de la Universidad Luliana y Literaria de Mallorca (Madrid, Dykinson - Carlos III, 2011).

PlatzeCK, E. W., "Introducción" a Explanatio compendiosaque applicatio Artis Raymundi Lulli (Hildesheim, Gerstenberg, 1977). 
Pontes, J. M. Da Cruz, Raimundo Lulo e o lulismo medieval portugués, en Biblos, 62 (1986), pp. 51-76.

Puig Oliver, J. de, La filosofia de Ramon Sibiuda (Barcelona, Institut d' Estudis Catalans, 1997).

Raimundi Lulli Opera Latina(2007), XXXI.

Raimundi Lulli Opera Omnia (1737), VI.

Ramis Barceló, R., "Estudio Preliminar" en Ramon Llull, Arte de derecho (Madrid, Carlos III, 2011).

Ramis Barceló, R., Un esbozo cartográfico del lulismo universitario y escolar en los Reinos Hispánicos, en Cuadernos del Instituto Antonio de Nebrija de Estudios sobre la Universidad, 15 (2012) 1.

Reinhardt, K. (editor), Heymericus de Campo. Philosophie und Theologie im 15. Jahrhundert (Regensburg, Roderer, 2009).

Rodríguez Puerto, M. J., La Modernidad discutida, Jurisprudencia frente a iusnaturalismo en el siglo XVI (Cádiz, Servicio de Publicaciones de la Universidad de Cádiz, 1999).

Rossi, P., Clavis universalis. Arti mnemoniche e logica combinatoria de Lullo a Leibniz (Milano-Napoli, Ricardo Ricciardi, 1960).

SAvignY, F. K. von, Geschichte des Römischen Rechts im Mittelalter (Heidelberg, 1850), $\mathrm{V}$.

STINZING, R., Geschichte der deutschen Rechtwissenschaft (München, Oldenburg, 1880-1884), II.

Trias Mercant, S., Diccionari d'Escriptors lul.listes (Palma, UIB-UB, 2009).

Vasoli, C., Profezia e ragione. Studi sulla cultura del Cinquecento e del Seicento (Napoli, Morano, 1974).

VICTOR, J., Jacques Lefevre d'Étaples, Charles de Bovelles and Bernardo de Lavinheta: The Revival of Lullism at Paris, 1499-1516, Renaissance Quartely, 28 (1975).

VIEHWEG, T., Tópica y jurisprudencia (Madrid, Taurus, 1986).

WIEACKer, Franz, Humanismus und Rezeption, en Rechtslehrer der neueren deutschen Privatrechtsgeschichte (Gottingen, Vandenhoeck und Ruprecht, 1959).

Wohlhaupter, E., Die "Ars brevis, quae est de inventione mediorum iuris civilis" des Ramon Lull (segunda parte), en Estudis Franciscans, 47 (1935). 